\title{
What's the "Big Deal”, and why is it a bad deal for universities? David Ball
}

\section{The author}

David Ball is University Librarian at Bournemouth University and is a leading practitioner in the field of library purchasing consortia. He chairs Procurement for Libraries and the Libraries Group of the Southern Universities Purchasing Consortium, and has negotiated ground-breaking agreements with suppliers for services and materials. He is a Member of the Board of the South West Museums, Libraries and Archives Council, and plays a leading role in regional library affairs in the UK. He also has experience in the private sector, as information manager for a major newspaper publisher.

Keywords: Big deal; electronic journals; publishing; procurement.

\begin{abstract}
At first sight the "big (or all-you-can-eat) deal" seems excellent value for libraries and their users, and represents the shining possibilities of the electronic age. A more thorough-going evaluation, however, exposes dangers for universities, their funders and publishers. This paper examines the big deal in the light of fundamental market conditions and suggests alternative models for procuring electronic resources.
\end{abstract}

The roles and strengths of the players in the information supply chain are defined: creators, publishers, intermediaries, libraries. Traditional hard-copy procurement is analysed in terms of these roles and the concepts of authority, branding and monopoly. The (often overlooked) role of and benefits secured by hard-copy purchasing consortia are examined. Cost savings are shown to arise from competition in the market-place.

The fundamentals of procuring electronic resources and prevalent purchasing models are discussed in terms of the same roles and concepts. The advantages of the big deal are laid out - access to resources, low unit costs etc. The dangers are also discussed. These arise mainly from the publishers' position as monopolists. The possible long-term effects, on library budgets and academic publishing, of dealing with monopoly suppliers are examined.

Means of avoiding or minimising these dangers - consortia, alternative publishing methods, new economic models to promote competition - are examined.

This article is a revised and updated version of a paper given at the IATUL conference held in Ankara, Turkey in 2003.

\section{Introduction}

There is a common European folk-tale, often called 'the little porridge pot'. It tells the story of a family of hungry peasants who are given a magic cooking pot by the usual mysterious outsider. They are told two words of command: one makes the pot produce an endless supply of porridge; the second makes it stop. The pot will obviously change 
the peasants' lives: hunger, and the fear of it, will be banished by a ready, endless supply of food: humble, monotonous perhaps in modern eyes, but a nourishing staple. All is well; the peasants no longer go to bed hungry.

However, one day the daughter of the family is left alone in the peasants' cottage. She instructs the pot to cook; unfortunately she has forgotten the word of command to make it stop. When the rest of the family returns that evening, the village and fields are covered in a sea of porridge, which is starting to invade the forest.

As with all folk-tales, there are many resonances for the modern world. We live in an information-hungry society. The electronic medium, delivered through the desk-top porridge-pot, offers a means of stilling that hunger. However the message of this paper is that, just like the little porridge pot, electronic information is not an unalloyed good: it has dangers and threats for the continuance of publishing and the library profession. In particular our freedom to choose and shape our collections is being eroded, and the power of the large electronic publishers is growing.

This paper discusses:

- the information value chain and some of its concepts, paying particular attention to features differentiating electronic from printed information;

- money as an indicator of value;

- the implications of the publishers' monopoly for pricing and negotiation;

- the implications of the product-to-service shift for archiving and access;

- business models for e-resources, particularly the big, or all-you-can-eat, deal;

- the loss of control by librarians and strategies to regain control.

The opinions expressed are my own and do not necessarily represent the views of Bournemouth University.

\section{The information value chain}

Following Mark Bide's useful taxonomy, we can identify the following activities or functions in the information supply chain: creation, publication, aggregation, access and use. ${ }^{1}$ To a greater or lesser degree, each of the activities, or links, adds value to the information, until it is used and the value realised. This account is somewhat simplified: I shall not discuss exhaustively the roles of all the players in the chain, but concentrate on the key ones. Some of the main concepts applied during this discussion are: branding, authority, monopoly, and the product-to-service shift.

Each link in the chain confers an element of branding or authority on the information. Authority has to do with reliability, informed opinion, having status or expertise. One thinks for instance of the BBC: a news broadcast in the World Service carries a great deal

\footnotetext{
${ }^{1}$ I am indebted to Mark Bide for his analysis of the information value chain in the 1998 study for ECUP+: Business models for distribution, archiving and use of electronic information: towards a value chain perspective.
} 
of authority. Branding has to do with consistency and quality. Examples might be CocaCola and Pepsi Cola: these are different brands, with different qualities, consistent in themselves and having different adherents.

Each link in the chain also has a greater or lesser degree of monopoly. This is particularly important for the information market place. I shall therefore highlight where monopolies and competition lie, how they can be used to advantage, and the problems they cause the purchaser or user.

One major factor differentiating electronic from printed information is the shift from product to service. With printed information, much labour and cost are tied up in producing, distributing, storing and handling a physical product: books and serials. With electronic information, libraries and other intermediaries generally only deal in access to information held in a remote location, a service not a product. It is worth noting that this shift follows a general trend, as companies and public bodies outsource more and more activities.

\subsection{Creation}

Creation is a familiar concept, and needs no long discussion. Creators may be authors or compilers. They may be directly employed by publishers, as are journalists and technical writers. Alternatively they may be independent agents.

Particularly in popular fiction, the creator confers authority. One obvious example is Stephen King: picking one of his novels from the shelf one knows what one is getting. On the cover it is his name, not the title, that has prominence. The creator is also a monopolist: only Stephen King produces his novels. This monopoly, protected by copyright, is then generally transferred to a single publisher.

\subsection{Publication}

Publication is essentially concerned with the selection and editing of information into consumable form. In one sense it is a form of quality control.

Publishers also package information into usable and buyable units (titles, series, journals), market the product, and undertake, or subcontract, physical production and distribution.

For librarians, authority is conferred in part at least by the imprint - Oxford University Press, for instance, or Butterworths. The end-user is more likely to focus on the brand British Medical Journal, Nature or Who's Who. This holds equally true for academic publications, where the editorial and refereeing process is concentrated at the level of the title, as for general publications.

The publisher's monopoly, often transferred from the creator, is also jealously defended.

For those involved in procurement, the delivery of information in electronic form embodies some important differences from the delivery in printed form. 
There is essentially no physical production and distribution of electronic information. There is a physical realisation at the moment of use - as an image on a computer screen or a print-out. But this occurs only at the end of the information chain, not close to the origin, as happens with print. For the rest of the chain we are talking about access to the information, not a physical product containing the information. We, as purchasers, are therefore now buying a service as opposed to a physical product.

We should also note that, with electronic information, authority is potentially diluted. It is easy to publish and disseminate information on the web, far easier than publishing and disseminating in print, which require considerable investment of money and time. It has become correspondingly difficult to establish the authenticity and provenance of information.

\subsection{Aggregation}

One may define aggregation as: bringing together in a coherent collection disparate information sources. Clearly this is core territory for the information professional. The traditional activity of acquisition that formed our large historic libraries is now increasingly underpinned by the procurement process and the support and expertise of procurement professionals, who are bringing greater regulation and management into this process and increasing value for money for their institutions.

Libraries confer authority by virtue of selecting material. Users, whether students or members of the public, perceive a certain warranty of fitness for purpose if a book is on their library's shelves. Libraries also have a perhaps unrecognised near monopoly on such aggregations of printed information. There are few alternatives, except a bookshop, where stock, facilities and opportunities for consultation and loan are severely limited or impossible.

It is important to note in this context the accent on the physical product. Much of a traditional library's work deals with acquiring, processing and handling these physical products. Increasingly, as far as the acquisitions process goes, this is subcontracted or outsourced to intermediaries, such as booksellers or serials agents.

With electronic information, there is no physical product to acquire or handle. The role of aggregator therefore moves elsewhere in the supply chain, to the publisher or intermediary such as the serials agent. There is also a trend to 'virtual' aggregation, with services such as CrossRef www.crossref.org, where the articles of major serials publishers are linked, while remaining on servers run by the publishers themselves.

The collective and near monopoly of libraries, evident for printed information, is therefore lost: users need set foot nowhere near a library to have access to aggregators' sites; they simply need a network connection, and either the appropriate permissions or deep pockets. 


\subsection{Access}

Facilitating and controlling access to aggregated printed information is again core territory for libraries, needing little explanation.

Selective dissemination of information raises awareness. Catalogues, bibliographies and indexes aid discovery and location. User education, particularly in academic libraries, trains users in gaining efficient access to and effectively exploiting information. Library management systems control access to collections.

Libraries here too have a perhaps unrecognised near monopoly on providing access and the tools that support it.

Providing access to electronic information is however fundamentally different.

One prerequisite is a robust IT infrastructure to deliver the information. In the UK this infrastructure is well established in academic libraries and is now extending to the citizen following recent investment in the public library sector.

However, many of our users have their own PCs and Internet connections. Soon set-top boxes will deliver Internet connectivity through the television screen. Provision and installation of such set-top boxes may follow the pattern established by mobile phone companies, which gave away the hardware in order to be able to sell services. Libraries therefore are fast losing the monopoly on access: the majority of our users may soon be able to connect to information resources more easily from their living rooms than from a terminal in a library.

One can also foresee existing providers of online services offering alternative public information services. The local supermarket might offer community information, adding value in order to ensure customers return to the site for their online shopping. Why should our users move from the comfort of their homes to use our connectivity? Why, even, should they connect to, say, a public library website when a commercial website they use frequently fulfils their perceived information needs?

One supplier of e-books deals only with end-users, not libraries. One 'quotation' on its website from a satisfied customer reads: "I got an A+ using this library. It's so much easier than the regular library.”

Libraries' collective near monopoly on providing and facilitating access to information is therefore lost. However, authority is also diluted. How far can one trust the information offered as an add-on by a commercial service-provider? For the time being libraries will retain the authority conferred by their traditional roles as selectors and organisers of information resources.

\subsection{Use}

Finally we arrive at the end of the chain and its reason for existence, the user, who, of course, particularly in the academic sector may also be the start of the chain.

Hitherto we have stressed that, for traditional printed resources, we have been dealing with a physical product. What we provide to the user is however a service - access to the information - not the physical product itself. Even in the case of photocopies and 
document delivery, a little thought should demonstrate that this is so: the product is returned to the shelf.

Here we also have one of the conundrums of the information chain: how, particularly in the traditional print environment, do we measure actual usage of acquired stock? We as librarians routinely collect statistics on loans, footfall etc. But how well do these statistics reflect actual usage? Of five items borrowed only one may be used or needed; the rest may be rejected by the borrower for whatever reason. Also, how can we effectively measure reference usage within the library, and how many libraries regularly and accurately do so?

Furthermore, particularly if we only have a very blunt measure of usage, can we equate apparent usage with value to the end-user? If we cannot, how can we justify our purchasing decisions?

Holding information electronically offers some help here: it opens the possibility of more accurately recording and measuring usage, as expressed in access to and downloads of particular texts or services. It is also possible to envisage systems of payment for such usage, either through actual cash transactions or through users having and exchanging a number of credits. Holding information electronically therefore opens the way to more accurate measures of both usage by, and value to, the end-user.

\section{Money and as indicator of value}

Let us take a little time to chart the flows of money through the value chain, and to reflect on where it sticks.

Beginning with the independent creator (i.e. one not employed to write) we note that in popular fiction the rewards tend to go to the author. Stephen King and Tolkien are commodities: their creativity is the point of scarcity, and points of scarcity tend to attract money.

Scholarly and academic authors, on the other hand, are generally paid nothing, or next-tonothing, for their output. Scholarly journals obviously cannot exist without their output, but this dependence is not recognised in economic terms. It is the publisher, not the author, who reaps the direct financial rewards of publication. This is reflected, for instance, in the profits of the big academic publishers. Thus Houghton notes that "in 1997 Reed Elsevier enjoyed a higher net profit margin than 473 of the S\&P 500 listed companies, Wolters Kluwer provided higher return on equity than 482 of the S\&P 500, and margins generated in the science, technical and medical publishing areas of the companies tend to be even higher than aggregate margins". ${ }^{2}$

So what are they rewarded for? Publishers in effect provide two services: firstly they disseminate information; secondly they confer authority by ensuring quality.

\footnotetext{
${ }^{2}$ John Houghton, Economics of scholarly communication: a discussion paper prepared for the Coalition for Innovation in Scholarly Communication, Canberra: The Coalition, 2000, p.65; available at: http://www.caul.edu.au/cisc/EconomicsScholarlyCommunication.pdf
} 
Dissemination can be achieved by anyone with a network connection: scholars and professionals regularly use e-mail and other similar means of disseminating results. Dissemination is not therefore a point of scarcity. This conclusion is supported by an examination of the rewards of intermediaries, which shows an interesting difference between booksellers and serials agents. Booksellers are a much more valued part of their supply chain. They can command very high discounts from the publisher, particularly for popular fiction, where authority or branding derives from the author. Thus we see discounts of 50\% in some supermarkets off the prices of popular books. Serials agents, on the other hand, command very low margins on hard copy - an average of $7 \%$ has been cited.

It seems therefore that scholarly publishing in academic journals is essentially about validation of results through the editorial and peer-review process rather than dissemination. Guédon traces this process of validation, of creating the scholarly record, of establishing paternity and property rights, back to the $17^{\text {th }}$ century, where it is already evident in the first issues of the Philosophical transactions of the Royal Society of London. $^{3}$

It must be remembered that scholarly and academic authors do reap indirect rewards from publication. Publication, particularly in prestigious peer-reviewed journals, leads to promotion and to research funding. There is of course institutional, as well as personal, interest, in such publication: the funding and prestige of institutions is generated in large measure by their scholars. This institutional interest is particularly evident in the UK, where the quinquennial Research Assessment Exercise ranks university departments and disburses large sums of money to the best.

There is therefore a large financial interest, on the part of both individual scholars and their employing institutions, in continuing to play the game of scholarly publication in existing established peer-reviewed journals; this may explain, in part at least, why new electronic initiatives outside traditional publishing have not taken off.

Another interesting characteristic of the financial side of scholarly publishing is that the user or consumer in general does not pay for the information used. ${ }^{4}$ Payment is made from an institutional budget, generally delegated to the librarian. The user is therefore insulated from considerations of cost and the effects of inflation: unlike most products price does not affect demand because the user is not obliged to place a value on the product consumed.

\footnotetext{
${ }^{3}$ Jean-Claude Guédon, 'In Oldenburg's long shadow: librarians, research scientists, publishers, and the control of scientific publishing', ARL proceedings, 138, May 2001, p.3; available at

http://www.arl.org/arl/proceedings/138/guedon.html.

${ }^{4}$ Fines are levied not for the information delivered but for transgressions against an institutional code. Charges for photocopies are for the convenience of the user not for the actual information. Likewise charges for document delivery are generally for the direct costs incurred.
} 
We see therefore that academic publishers claim the rewards by virtue of fulfilling a need of scholars and institutions for validation. Their monopoly has allowed them to inflate prices, unchecked by a market where the user is insulated from the effects of inflation.

\section{The power of consortia?}

Traditionally libraries have bought content from intermediaries: aggregators such as booksellers and serials agents. Over the past ten years in the UK such dealings have been carried out increasingly through consortia. The seven UK regional higher education consortia currently have contracts with booksellers and serials agents worth over £70m a year.

Such aggregation of purchasing power brings many advantages. New services such as the truly shelf-ready - catalogued, classified and processed - book have been negotiated through the strength of consortia. Quality of service is monitored closely and enhanced through continuing management of contracts based on tight specifications of service; pooled knowledge of suppliers' performance against these specifications lends force to this process. There are considerable savings in terms of the time needed by individual libraries to manage complex European Commission procurement procedures and the resulting contracts. Quite startling discounts on books have been obtained by UK consortia, for both public and academic libraries. These discounts are given from the intermediary's margin: the difference between the cost of a book to the intermediary and the published price. The intermediaries are in competition for market share, and will therefore cut prices and offer services that add value in order to gain such market share.

With e-resources, particularly e-journals, consortia are more likely to negotiate with publishers. The economic imperative for publishers is very different from that for intermediaries. Let us take a simple hard-copy example. If the publisher discounts the library price of a well respected journal by $50 \%$ its is most unlikely that subscriptions will double. Some libraries will take an additional copy; there will be less cancellations; but the number of subscriptions will not rise hugely. Instead libraries will spend the saving on other titles, from other publishers. By discounting, the publisher has lost profitability and decreased market share, hardly good business. The converse is also true. If the library price of the well respected journal is doubled, some subscriptions will be lost, but since the title is well respected, by no means 50\%: other journals will be cancelled instead. By raising the price the publisher will increase profitability and market share. The disconnection already noted of user, the only true judge of value, from price paid has fed the rampant inflation seen in hard-copy journal prices.

The same commercial logic applies in electronic publishing. It makes no sense for the publisher to offer discounts to the individual library, still less to the consortium. By so doing he would simply and immediately decrease both profit and market share. What publishers offer instead of lower prices is additional content. As we shall see below, this bundling puts the publisher in an even stronger position vis-à-vis libraries. ${ }^{5}$

\footnotetext{
${ }^{5}$ For an accessible introduction to the economics see: Richard Poynder, 'A true market failure: Professor Mark McCabe talks about problems in the STM publishing industry', Information today, 19 (11),

December 2002, available at: http://www.infotoday.com/it/dec02/poynder.htm. For a full treatment see
} 


\section{The product - to - service shift}

We have delineated a new feature of the information value chain that has, I believe, weakened our position still further: the shift from buying a product to buying a service.

When we buy a physical product - a book or a journal - our users will have access to it in perpetuity. There are risks - it may be lost or vandalised or read to destruction - but we can take steps to minimise these risks. The point is that we are physical curators and in control: the right to the object is inalienable, even if there are restrictions on rights to its content. Our users know that, all things being equal, they may return to our shelves in five or ten years' time and retrieve the same item.

However, in the electronic world we do not buy and own a physical product; we buy, generally, a time-limited licence that confers certain rights of access to content. There are important differences here.

Firstly, such licences do not necessarily offer archival rights: in such cases our users do not have continuing rights of access to material beyond the term of the licence. Many of us involved in consortia take a stand against the loss of archival rights. BIBSAM in Sweden, for instance, has refused recently (March 2003) to continue an agreement with AAAS for access to Science Online in part at least because of a refusal to include archival rights. This refusal produced the interesting reaction from Science Online that only consortium administrators insist on archival rights; individual libraries do not. This is understandable: libraries, under immediate pressure from their users, are likely to sign agreements giving the benefits of electronic access, however imperfect; individual libraries are also quite likely to continue to purchase parallel hard copy to guarantee continuing archival access.

Secondly, the content to which we buy rights may change. Titles, imprints and companies may be bought, sold, transferred. There is a well known example in the UK of an intermediary selling to public libraries a deal comprising access to national newspapers; all was well until the newspapers became concerned at the potential loss of revenue from CD-ROM sales and withdrew their titles. There are also well documented examples on the e-mail lists of individual published articles being subsequently withdrawn. In short, there is no guarantee of continuing access to content.

Thirdly, licences may restrict access to content to particular classes of user. In the UK there is an increasing trend, encouraged by the government, to teaching higher education courses in colleges of further education. However licences may restrict usage to a particular site or to a particular institution, excluding students and staff elsewhere. Our freedom to determine who may have access to our resources has been forfeited.

Mark J. McCabe, Academic journal pricing and market power: a portfolio approach, 2000, available at: http://www.prism.gatech.edu/\%7Emm284/JournPub.PDF. 


\section{Business models}

The most remarkable business model to have emerged in electronic publishing is the socalled big, or all-you-can-eat, deal. This is particularly prevalent in the field of ejournals, but may also be seen in the field of e-books.

Under the big deal, a journal publisher will grant access to all their titles for three or five years. There is an annual subscription, often based on the cost of the subscriber's previous print subscriptions, with some built-in increase for inflation and generally a nocancellation clause. Libraries and their users will therefore have access to all of the publisher's content spanning however many years are available in the electronic archive.

There are potential benefits for both sides. Users have immediate access to material previously not subscribed to at no incremental cost. Libraries can predict inflation over the term of the agreement, and save money from the document supply budget. Publishers have a stable revenue stream for a number of years, with no cancellations.

However, things are seldom as straightforward as they seem.

There is some statistical evidence to show that users are downloading or hitting articles well outside the range of the previously subscribed core of hard-copy titles. Understandably this has caused librarians a fair amount of anguish, since it implies that our past collecting policy has been ill advised.

However, we have to treat this evidence with some caution. It has not been collected for very long: it offers a short time series at the start of a new service. There is no real comparison with previous data: librarians have generally not collected usage data for their journals, partly because much consultation of them has been within the library. There is also the sweet-shop syndrome: children suddenly given the freedom of a sweet shop will gorge initially far beyond the value of their pocket money before their appetites stabilise. The take-up of articles by academics may decline too over time as the novelty disappears. Also, we may be observing the substitution of full article hits or downloads for previous use of abstracting services: because the download or consultation is free, academics may use that mechanism where they would previously have been satisfied with an abstract. In other words the distortion that we noted above, arising from the divorce of the user from the cost of the information, is magnified. We are perhaps even further away from measuring value to the consumer, rather than usage.

In my opinion therefore the prima facie case that the big deal offers major benefits in terms of access to information is not necessarily proved. Indeed there is some countervailing statistical evidence. Hamaker for instance notes that $28 \%$ of Science Direct titles accounted for $75 \%$ of downloads at the University of North Carolina. 34\% of titles had five downloads or less. $40 \%$ of usage occurred in a single month for $57 \%$ of titles. $^{6}$ Nicholas's initial study of the Emerald big deal shows that $43 \%$ of subscribers

6

6 Chuck Hamaker, 'Quantity, quality and the role of consortia', What's the Big Deal? Journal Purchasing Bulk Buying or Cherry Picking? Strategic issues for librarians, publishers, agents and intermediaries, 
viewed only one journal out of 118 ; another $40 \%$ viewed $2-5$ journals. So $83 \%$ of subscribers viewed less than $5 \%$ of the available titles. $44 \%$ of subscribers viewed only one subject area out of about 10; a further $19 \%$ viewed only 2 subject areas. ${ }^{7}$

The core collection, it seems, is still alive and well.

There is also a hidden danger in the availability of the full output of some of the bigger publishers. Guédon traces the influence of the citation indexes' documentation of impact factors for journals in creating a core collection of must-have journals for particular disciplines. He also posits an increase in citations of the journals of big deal publishers (understandable given their availability) in the research output of subscribing universities. ${ }^{8}$ We have therefore potentially a vicious circle where the journals in big deals have higher and higher impact factors, to the detriment of journals outside the big deals. The effect on the market-place will be to undermine the financial viability of such journals and their (generally smaller) publishers.

The big deal is also challenging for librarians. Under it we no longer take the decisions on developing our collections that we have been used to (not necessarily a bad thing, some would say, on the basis of some of the statistics mentioned above). We shall increasingly decide on content not at the journal level but at the publisher level. This is a qualitative change and one that does not necessarily work in our or our users' favour. The user is focused on the article, to a lesser extent on the journal title, and most certainly not on the publisher. In the electronic environment, where the physical package - the title - is no longer necessary for purchase, our aim surely should be to increase the granularity of decision making, not decrease it.

I believe that the big deal may also presage a further unwelcome effect on the market place. We recall that publishers are monopolists: only they own the rights to their content and determine the terms. In the environment of consumer publications there is some substitutability: instead of buying The Times one can buy The Independent; they are different brands but with very similar news content. However, in the academic world there is virtually no substitutability of primary content: if Researcher A needs the published results of Researcher B, the results of Researcher $C$ will not do; if results in Researcher A's field are published in Journal Y, Journal Z will not do. The big deal commits a library to either buy or cancel the entire content of a monopolist: the monopoly is thereby intensified. The monopoly is intensified even further in the case of national deals covering an entire library sector. Such intensification cannot be in the interests of the purchaser.

ASA 2003 conference; available at http://www.subscriptionagents.org/conference/200302/chuck.hamaker.pps.

${ }^{7}$ David Nicholas and Paul Huntington, 'Big deals: results and analysis from a pilot analysis of web log data: report for the Ingenta Institute', in The consortium site licence: is it a sustainable model? Edited proceedings of a meeting held on $24^{\text {th }}$ September 2002 at the Royal Society, London, Oxford: Ingenta, 2002 (Ingenta Institute, 2002), pp121-159, pp149, 151.

${ }^{8}$ Guédon, p.24 
There is also a danger that, at renewal time, publishers can offer libraries a stark choice: pay an additional $50 \%$ (or more) for the big deal or cancel. Few academic libraries will be able to refuse the big deals, because they contain so many must-have titles. The inflation we have seen for hard-copy titles, enabled by the disconnection of user from price paid, will now be further fuelled by bundling into the big deal. The consequence will therefore be that journals outside the big deals will be cancelled. Publishers, particularly the smaller ones will cease trading, and there will be further consolidation in the marketplace.

I have dwelt here on e-journals, as the more mature electronic market. A similar characteristic is also evident in the e-books market, where some aggregators offer the equivalent of the big deal: one subscribes to all or nothing, or to business or IT libraries of several hundred titles. Again there is no selection at the individual title level, only at the library or publisher level.

It must however be said that there is also a countervailing trend in the e-book market, where at least one intermediary enables libraries to subscribe title by title and to change these titles every month.

It must be in our interests as librarians and purchasers to encourage those trends and the suppliers that offer us the flexibility and granularity that we and our users require.

\section{What can libraries do?}

We have seen that the marketplace is changing, that the big publishers are introducing business models that seem to benefit the user but that are potentially dangerous in their effects, threatening the viability of the smaller publishers and exacerbating the tendency to consolidation.

There are a number of measures we can take to strengthen both the position of libraries and to change the publishing environment.

Firstly, in spite of what I have said above, we can form and support library consortia. These can be powerful entities, particularly when they take a holistic view uniting procurement of both print and electronic resources: publishers produce and deal in both media; we integrate print and electronic forms in our hybrid libraries; we should integrate their procurement too. They are the only library organisations that have a chance of affecting the marketplace; individual libraries certainly do not, given the conditions outlined above.

Secondly we can follow the normal procurement process. Currently we have let suppliers, the publishers, take control. We can regain it by observing the standard procurement cycle: 


\section{i. Identify the need \\ ii. $\quad$ Prepare the specification \\ iii. Find the supplier \\ iv. Award the contract \\ v. Measure and monitor suppliers’ performance}

This cycle, particularly through the specification and by monitoring performance against that specification, puts the purchaser firmly in control. Admittedly such control is easier to achieve where there is competition between suppliers (e.g. booksellers or serials agents) and not a monopoly as with publishers. However by allowing the publishers to dictate the terms of engagement we are ceding too much.

Thirdly we can support alternative publishing initiatives such as SPARC. As we have discussed above, traditional hard-copy publishing in peer-reviewed journals is deeply entrenched because of institutional and personal interests in the scholarly community. These initiatives can however be held up as alternatives, even if there is little chance that in themselves they will become rivals to traditional publishing. As Guédon remarks, ${ }^{9}$ pitting SPARC against the big publishers is like pitting David against Goliath; in my view there is the added disadvantage that Goliath has chosen a stone-free field of battle.

Finally, we can involve our users more. Many of the current and historical problems are exacerbated by divorcing the user from payment for information. I do not suggest that the user should be made to pay, rather that the economic consequences of their demands should be made clear to them. We can involve them more in the procurement cycle outlined above: how many consortia or individual libraries consult the end-user about the specification or include them in contract management?

Furthermore, electronic publishing allows procurement decisions at a greater level of granularity - the individual article or chapter. One demonstration of this was the Pricing Electronic Access to Knowledge (PEAK) trial in electronic access, pricing and bundling by the University of Michigan and Elsevier Science. ${ }^{10}$ It provided access to approximately 1200 Elsevier Science journals for a period of 18 months. Institutions first had to buy a participation licence, which allows searching of the database of articles. PEAK then offered three access models:

- Traditional subscription - Institutions and individual users can buy unlimited access to a set of articles that correspond to a print journal title.

- Generalised subscription - Institutional users can buy unlimited access to bundles comprising any 120 articles from the entire database of priced content. Articles are

\footnotetext{
${ }^{9}$ Guédon, p.16.

${ }^{10}$ For a more detailed analysis of the PEAK experiment see the author's 'The information value chain: emerging models for procuring electronic publications', Online information 2000: $24^{\text {th }}$ International Online Information Meeting: proceedings, conference editor Catherine Graham (Oxford: Learned Information Europe, 2000), pp.213-223. Detailed original reports may be found on: http://www.lib.umich.edu/libhome/peak/
} 
selected after the fact of subscription and may be accessed by all authorised users at the institution.

- Per Article - Individual users can buy limited access to a specific article for a fixed price.

PEAK is a most interesting model for almost the whole of the information chain: to the publisher it offers some degree of stability of income and the possibility of tapping budgets presently devoted to document delivery; to the library and its patrons it offers flexibility of collection and selection combined with budgetary control; it also offers the possibility of devolving purchasing decisions to the end-user.

The traditional subscription model is similar to hard-copy subscription, facilitating the purchase of core 'cover-to-cover' titles. The generalised subscription model breaks the tyranny of the title, allowing libraries to build the eclectic collections their users require. Publishers would retain their position of authority, through the editorial process, but the importance of branding inherent in the serial title would diminish.

The purchasing decisions in the generalised subscription (and per article) models can be devolved as the institution wishes: to the subject librarian, to faculty representatives, to individual members of academic staff or even the student body. This devolution helps to overcome the chief disconnection of user from price noted above: individual users are much closer to controlling the spending of budgets in accord with their needs. This should result in better value for money from library spending.

A generally applied PEAK model, with the major publishers participating, might also have interesting implications for the position of publishers as monopolists. With purchasing decisions made at the level of the individual article, there may be more intense competition between publishers on content, price and terms of use.

My feeling is that few publishers will be brave enough to open themselves to this type of competition. But new business models, such as PEAK, seem to me to be the only bright prospect on a darkening horizon.

\section{Vale}

Returning to our opening folk-tale, the little porridge pot on everyone's desk is a major benefit in satisfying information hunger. However it is vital that we, the purchasers, retain control of it by not forgetting the magic words of command, or relinquishing them to others. 